\title{
The productivity evaluation model and its application for finite conductivity horizontal wells in fault block reservoirs
}

\author{
Jiang Hanqiao ${ }^{1 *}$, Ye Shuangjiang ${ }^{1}$, Lei Zhanxiang², Wang Xing ${ }^{3}$, \\ Zhu Guojin ${ }^{3}$ and Chen Minfeng ${ }^{1}$
}

\author{
${ }^{1}$ Key Laboratory of Petroleum Engineering, Ministry of Education, China University of Petroleum, Beijing 102249, China \\ ${ }^{2}$ Research Institute of Petroleum Exploration and Development, PetroChina, Beijing 100083, China \\ ${ }^{3}$ Research Institute of China National Offshore Oil Corporation, Beijing 100027, China
}

(C) China University of Petroleum (Beijing) and Springer-Verlag Berlin Heidelberg 2010

\begin{abstract}
It is very difficult to evaluate the productivity of horizontal wells in fault block reservoirs due to the influence of fault sealing. On the basis of the method of images and source-sink theory, a semianalytical model coupling reservoir and finite conductivity horizontal wellbore flow dynamics was built, in which the influence of fault sealing was taken into account. The distribution of wellbore flow and radial inflow profiles along the horizontal interval were also obtained. The impact of the distance between the horizontal well and the fault on the well productivity was quantitatively analyzed. Based on this analysis, the optimal distance between the horizontal well and the fault in banded fault block reservoirs could be determined. According to the field application, the relative error calculated by the model proposed in this paper is within $\pm 15 \%$. It is an effective evaluation method for the productivity of horizontal wells in fault block reservoirs. The productivity of the horizontal well increases logarithmically as the distance between the horizontal well and the fault increases. The optimal distance between the horizontal well and the fault is $0.25-0.3$ times the horizontal well length.
\end{abstract}

Key words: Fault block reservoir, horizontal well, finite conductivity, productivity evaluation, well location design

\section{Introduction}

Fault block reservoirs are predominant in the eastern part of China. The initial oil in place and oil production account for $1 / 3$ of the total, respectively, in this area. Future reserves are likely found mainly in fault block reservoirs. A horizontal well can drain significantly larger reservoir volume than a vertical well and a larger contact area allows lower drawdown to recover more oil. Therefore, horizontal wells have been successfully applied in the development of fault block reservoirs (Zhou et al, 2006; Xie et al, 2008).

However, it is difficult to evaluate the productivity of horizontal wells due to the fault sealing in fault block reservoirs. Several models were proposed to evaluate the productivity of horizontal wells (Fan and Lin, 1994; Michelevichius and Zolotukhin, 2002; Fokker et al, 2003; Ye et al, 2009; Kuznetsov et al, 2010), but the effect of faults was not taken into account in these models, so the achievements could not be used in the productivity evaluation of horizontal

*Corresponding author. email: jhqlf@163.com

Received March 5, 2010 wells in fault block reservoirs.

In this paper, on the basis of the method of images and source-sink theory, a semi-analytical model coupling reservoir and finite conductivity horizontal wellbore flow dynamics is built. This takes into account the effect of fault sealing. The flow profiles along the horizontal well and radial flow into the wellbore are also obtained. The effect of fault sealing is quantitatively analyzed and the optimal distance between the horizontal well and the fault in fault block reservoirs is obtained.

\section{Reservoir flow model}

\subsection{Physical model}

The flow of fluids into a horizontal well is a complicated process and a three dimensional (3D) physical model was used to simulate the flow. Fig. 1 is the schematics of the model. In this paper we assume that a horizontal well penetrates through a fault block reservoir with closed boundaries (with impermeable top and bottom, right-hand and left-hand boundaries) and a single-phase fluid of constant 
viscosity and compressibility flows from the reservoir to the horizontal well under steady-state conditions. In order to study the well performance, the horizontal interval is divided into $N$ segments. In Fig. $1, h$ is the formation thickness, m; $a$ is the distance between the horizontal well and the fault in the left side, $\mathrm{m} ; b$ is the distance between the horizontal well and the fault in the right side, $\mathrm{m} ; z_{\mathrm{w}}$ is the distance between the horizontal well and the bottom of the reservoir, $\mathrm{m}$.

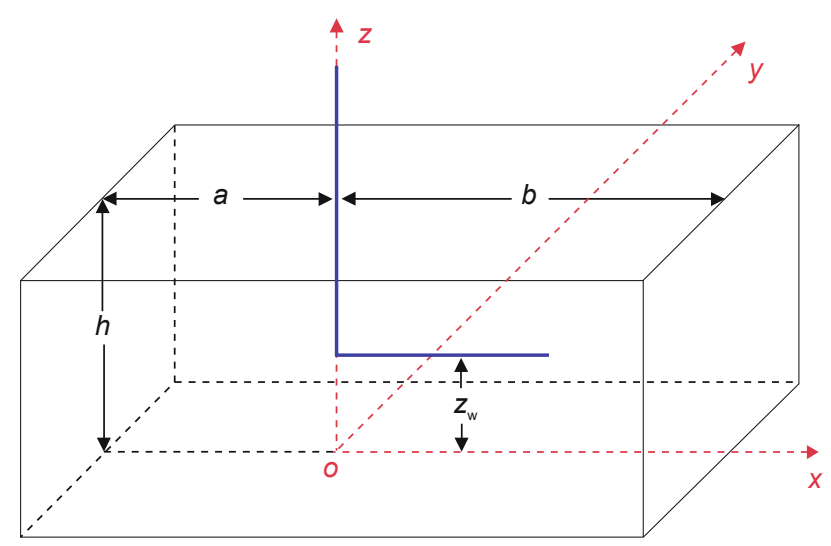

Fig. 1a Illustration of a horizontal well perpendicular to the faults

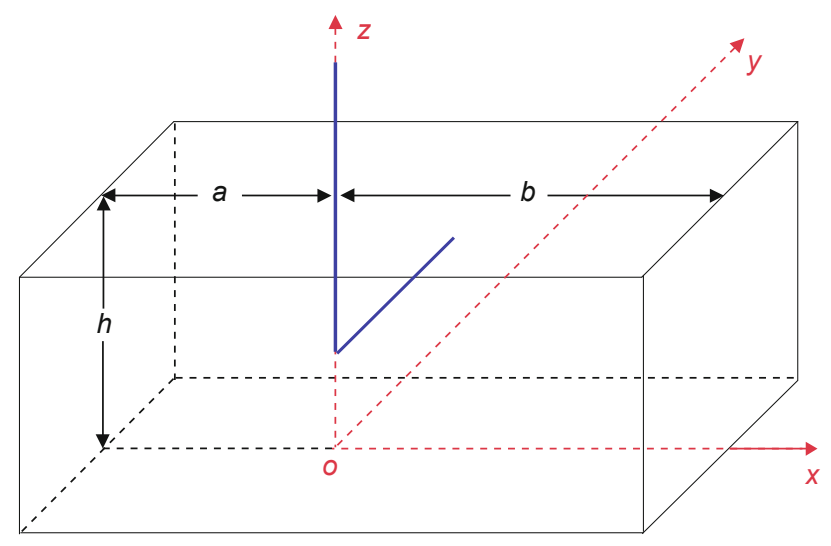

Fig. 1b Illustration of a horizontal well parallel to the faults

\subsection{Mathematical model}

When the horizontal well is perpendicular to the fault, the coordinates $(x, y, z)$ of an arbitrary point $M$ in the horizontal segment $i$ can be described by (Huang et al, 2005):

$$
\left\{\begin{array}{l}
x(i, t)=(i+t-1) \frac{L}{N} \\
y(i, t)=0 \\
z(i, t)=z_{\mathrm{w}} \quad(0 \leq t \leq 1)
\end{array}\right.
$$

where $x, y$ and $z$ are the coordinates of an arbitrary point in segment $i$, respectively; $L$ is the length of the horizontal interval, $\mathrm{m} ; N$ is the total number of segments.

When the horizontal well runs parallel to the fault, for segment $i$, the coordinates $(x, y, z)$ of an arbitrary point $M$ can be described by:

$$
\left\{\begin{array}{l}
x(i, t)=0 \\
y(i, t)=(i+t-1) \frac{L}{N} \\
z(i, t)=z_{\mathrm{w}} \quad(0 \leq t \leq 1)
\end{array}\right.
$$

The 3D diffusivity equation is:

$$
\frac{\partial^{2} p}{\partial x^{2}}+\frac{\partial^{2} p}{\partial y^{2}}+\frac{\partial^{2} p}{\partial z^{2}}=0
$$

The solution to Eq. (3) is substituted into the following boundary conditions:

$$
\left\{\begin{array}{l}
\left.\frac{\partial p}{\partial z}\right|_{z=0}=\left.\frac{\partial p}{\partial z}\right|_{z=h}=0 \\
\left.\frac{\partial p}{\partial x}\right|_{x=-a}=\left.\frac{\partial p}{\partial x}\right|_{x=b}=0 \\
\left.p(x, y, z)\right|_{(x-x(i, t))^{2}+(y-y(i, t))^{2}+(z-z(i, t))^{2}=r_{\mathrm{w}}^{2}}=p_{\mathrm{wf}}(i)
\end{array}\right.
$$

where $p_{\text {wf }}(i)$ is the bottom-hole flowing pressure for segment $i$, $\mathrm{MPa} ; p(x, y, z)$ is the pressure at any point $M(x, y, z), \mathrm{MPa}$.

As shown in Fig. 2, according to the method of images and the principle of superposition, we first project the horizontal well into an infinite number of image horizontal producers along the $z$ axis by the closed surfaces in the top and bottom. Then we project the infinite number of wells along the $z$ axis into two columns of image producers to account for the effect of the closed boundary in the left and right. The production of the image wells on the left and right sides of $z$ axis is half of that of the wells along $z$ axis. The coordinates of an arbitrary point of horizontal wells along $z$ axis can be described by:

$$
(x(i, t), y(i, t), 2 n h+z(i, t))
$$

and

$$
(x(i, t), y(i, t), 2 n h-z(i, t))
$$

The coordinates of an arbitrary point of image horizontal producers on the left side of the $z$ axis can be described by:

$$
(-2 a-x(i, t), y(i, t), 2 n h+z(i, t))
$$

and

$$
(-2 a-x(i, t), y(i, t), 2 n h-z(i, t))
$$

The coordinates of an arbitrary point of image horizontal producers on the right side of the $z$ axis can be described by:

$$
(2 b-x(i, t), y(i, t), 2 n h+z(i, t))
$$

and

$(2 b-x(i, t), y(i, t), 2 n h-z(i, t))$

By applying the principle of superposition, the potential at 
any point $M(x, y, z)$ in space is due to the contribution of all segments along the horizontal interval. The potential at $M(x, y$, $z)$ is:

$$
\begin{aligned}
& \Phi(x, y, z)=\frac{K}{\mu_{\mathrm{o}}} P(x, y, z)=\sum_{i=1}^{N} \Phi_{i}(x, y, z) \\
& =\frac{1}{4 \pi \Delta L} \sum_{i=1}^{N}\left[q_{\mathrm{r}}(i) \varphi_{i}(x, y, z)\right]+C
\end{aligned}
$$

with

$$
\begin{aligned}
& \varphi_{i}(x, y, z)=\sum_{n=-\infty}^{+\infty}\left[\xi_{i}\left(x_{i}, y_{i}, 2 n h+z_{i}\right)\right. \\
& +\xi_{i}\left(x_{i}, y_{i}, 2 n h-z_{i}\right) \\
& +\frac{1}{2} \xi_{i}\left(-2 a+x_{i}, y_{i}, 2 n h+z_{i}\right) \\
& +\frac{1}{2} \xi_{i}\left(-2 a+x_{i}, y_{i}, 2 n h-z_{i}\right) \\
& +\frac{1}{2} \xi_{i}\left(2 b+x_{i}, y_{i}, 2 n h+z_{i}\right) \\
& \left.+\frac{1}{2} \xi_{i}\left(2 b+x_{i}, y_{i}, 2 n h-z_{i}\right)\right] \\
& n=0, \pm 1, \pm 2, \cdots \\
& \xi_{i}\left(x_{i}, y_{i}, z_{i}\right)=\ln \frac{r_{1 i}+r_{2 i}+\frac{L}{N}}{r_{1 i}+r_{2 i}-\frac{L}{N}} \\
& r_{1 i}=\sqrt{[x(i, t=0)-x]^{2}+y^{2}+[z(i, t=0)-z]^{2}} \\
& r_{2 i}=\sqrt{[x(i, t=1)-x]^{2}+y^{2}+[z(i, t=1)-z]^{2}}
\end{aligned}
$$

where $\Phi(x, y, z)$ is the fluid potential at any point $M(x, y, z)$; $K$ is the permeability, $10^{-3} \mu \mathrm{m}^{2} ; \mu_{\mathrm{o}}$ is the oil viscosity, $\mathrm{mPa} \cdot \mathrm{s}$; $\Delta L$ is the length of each segment, $\mathrm{m} ; q_{\mathrm{r}}(i)$ is the radial flux for segment $i, \mathrm{~m}^{3} / \mathrm{d}$.

We introduce the following dimensionless variables (Ozkan et al, 1995; Yildiz and Ozkan, 1998).

$$
\begin{aligned}
& x(i, t)_{\mathrm{D}}=\frac{x(i, t)}{L / 2} \\
& y(i, t)_{\mathrm{D}}=\frac{y(i, t)}{L / 2} \\
& z(i, t)_{\mathrm{D}}=\frac{z(i, t)}{h} \\
& p_{\mathrm{wf}}(i)_{\mathrm{D}}=\frac{2 \pi K h\left(p_{\mathrm{e}}-p_{\mathrm{wf}}(i)\right)}{q_{\mathrm{t}} \mu_{\mathrm{o}}} \\
& q_{\mathrm{r}}(i)_{\mathrm{D}}=\frac{q_{\mathrm{r}}(i) \Delta L}{q_{\mathrm{t}}}
\end{aligned}
$$

$$
q_{1}(i)_{\mathrm{D}}=\frac{q_{1}(i)}{q_{\mathrm{t}}}
$$

where $q_{1}(i)$ is the flow rate along the horizontal well for segment $i, \mathrm{~m}^{3} / \mathrm{d} ; q_{\mathrm{t}}$ is the total flow rate, $\mathrm{m}^{3} / \mathrm{d} ; p_{\mathrm{e}}$ is the reference reservoir pressure, $\mathrm{MPa}$.

Eq. (5) can be arranged in the following form:

$$
\begin{aligned}
& \Phi(x, y, z)=\frac{K}{\mu_{\mathrm{o}}} P(x, y, z)=\sum_{i=1}^{N} \Phi_{i}(x, y, z) \\
& =\frac{q_{\mathrm{t}}}{4 \pi \Delta L^{2}} \sum_{i=1}^{N}\left[q_{\mathrm{r}}(i)_{\mathrm{D}} \varphi_{i}(x, y, z)\right]+C
\end{aligned}
$$

Once the distribution of the dimensionless radial flow rate $q_{\mathrm{r}}(i)_{\mathrm{D}}$ in each segment is known, all dimensionless flow pressure terms $p_{\text {wf }}(i)_{\mathrm{D}}$ can be calculated. Hence Eq. (12) is simplified to a linear equation system, and can be arranged in the following form:

$$
\begin{gathered}
{\left[\begin{array}{ccccc}
\varphi_{11} & \varphi_{12} & \varphi_{13} & \cdots & \varphi_{1 N} \\
\varphi_{21} & \varphi_{22} & \varphi_{23} & \cdots & \varphi_{2 N} \\
\varphi_{31} & \varphi_{32} & \varphi_{33} & \cdots & \varphi_{3 N} \\
\vdots & \vdots & \vdots & \ddots & \vdots \\
\varphi_{N 1} & \varphi_{N 2} & \varphi_{N 3} & \cdots & \varphi_{N N}
\end{array}\right]\left[\begin{array}{c}
q_{\mathrm{r}}(1)_{\mathrm{D}} \\
q_{\mathrm{r}}(2)_{\mathrm{D}} \\
q_{\mathrm{r}}(3)_{\mathrm{D}} \\
\vdots \\
q_{\mathrm{r}}(N)_{\mathrm{D}}
\end{array}\right]} \\
=\frac{2 \Delta L^{2}}{h}\left[\begin{array}{c}
p_{\mathrm{wf}}(1)_{\mathrm{D}} \\
p_{\mathrm{wf}}(2)_{\mathrm{D}} \\
p_{\mathrm{wf}}(3)_{\mathrm{D}} \\
\vdots \\
p_{\mathrm{wf}}(N)_{\mathrm{D}}
\end{array}\right]
\end{gathered}
$$

The flow rate $q_{1}(i)$ along the horizontal hole can be generalized as follows:

$$
q_{1}(i)=\sum_{k=i}^{N} q_{\mathrm{r}}(k)
$$

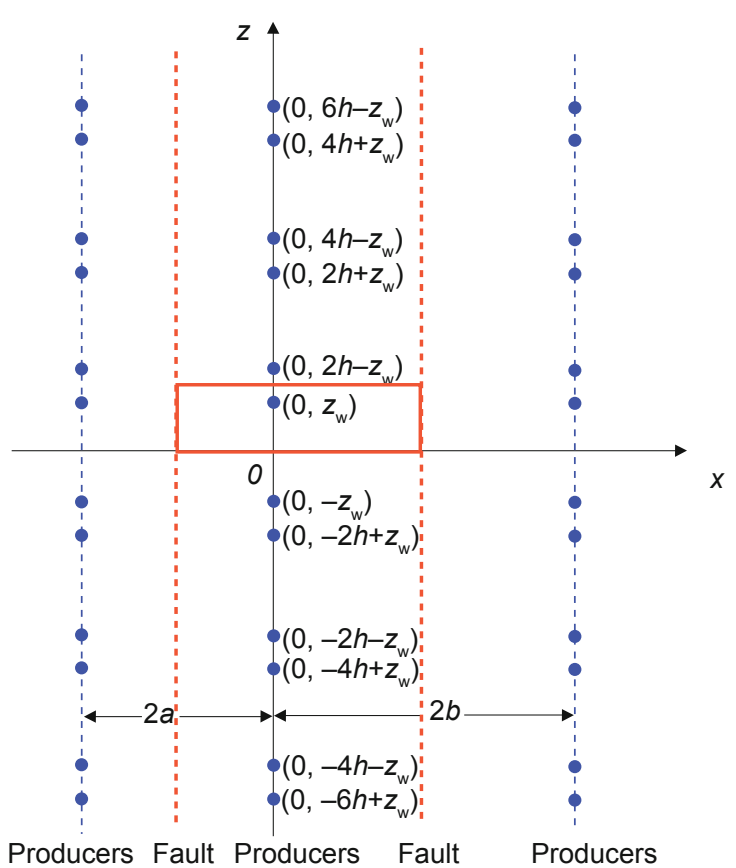

Fig. 2 Image wells of the actual horizontal well 


\section{Wellbore flow model}

The wellbore pressures of each segment along the horizontal interval are not independent, instead, they are related to each other via wellbore hydraulics. More specifically, the pressure difference between two neighboring segment midpoints is dependent on the radial flow into the two segments, local pressure, as well as the properties of fluids.

The pressure drop along the horizontal well is due to the wall friction and acceleration (Dikken, 1989; Ouyang et al, 1996; Tabatabaei and Ghalambor, 2009; Liu et al, 2000), which can be calculated by the pressure drop correlation proposed by Liu et al (2000).

$$
\begin{aligned}
& \Delta p_{\mathrm{wf}}(i)=\frac{L}{N}\left\{\frac{2 f \rho}{\pi^{2} D^{5}}\left[2 q_{1}(i)-q_{\mathrm{r}}(i) \frac{L}{N}\right]^{2}+\right. \\
& \frac{16 \rho q_{\mathrm{r}}(i)}{\pi^{2} D^{4}}\left[2 q_{1}(i)-q_{\mathrm{r}}(i) \frac{L}{N}\right] \\
& p_{\mathrm{wf}}(i)=p_{\mathrm{wf}}(i-1)+0.5\left(\Delta p_{\mathrm{wf}}(i-1)+\Delta p_{\mathrm{wf}}(i)\right) \\
& (1 \leq i \leq N+1)
\end{aligned}
$$

where $f$ is the friction factor; $\rho$ is the fluid density, $\mathrm{g} / \mathrm{cm}^{3}$.

$$
\begin{aligned}
& p_{\mathrm{wf}}(0)=p_{\mathrm{wf}} \\
& \Delta p_{\mathrm{wf}}(0)=\Delta p_{\mathrm{wf}}(N+1)=0
\end{aligned}
$$

Substituting Eqs. (9)-(11) and Eq. (14) and Eq. (15) into Eq. (16) yields

$$
f\left[q_{\mathrm{r}}(i)_{\mathrm{D}}, p_{\mathrm{wf}}(i)_{\mathrm{D}}\right]=0
$$

The number of equations in above two categories is:

.... Reservoir flow model: $N$ (Eq. (13))

.... Wellbore flow model: $N$ (Eq. (17))

The number of unknowns in above two categories is:

$$
\begin{aligned}
& \cdots \cdots \cdot q_{\mathrm{r}}(i)_{\mathrm{D}}: N \\
& \cdots \cdots \cdot p_{\mathrm{wf}}(i)_{\mathrm{D}}: N
\end{aligned}
$$

As expected, the total number of equations is also equal to $2 N$, which is the same as the total number of unknowns. Therefore, the problem is solvable and the solution should be unique.

\section{Solution procedures}

The iteration method was used to solve the system of equations. The solution procedure can be summarized as follows.

Assume the initial values of $p_{\mathrm{wf}}(i)_{\mathrm{D}},(1 \leq i \leq N)$, and substitute $p_{\text {wf }}(i)_{\mathrm{D}}$ into Eq. (13) to calculate $q_{\mathrm{r}}(i)_{\mathrm{D}}$. Then substitute $q_{\mathrm{r}}(i)_{\mathrm{D}}$ into Eq. (17) to update $p_{\mathrm{wf}}(i)_{\mathrm{D}}$. Substitute the new $p_{\mathrm{wf}}(i)_{\mathrm{D}}$ into Eq. (13) to update $q_{\mathrm{r}}(i)_{\mathrm{D}}$. Compare new $p_{\mathrm{wf}}(i)_{\mathrm{D}}$ and $q_{\mathrm{r}}(i)_{\mathrm{D}}$ with the results of the last iteration. If the differences are smaller than the specified tolerances, the iteration stops. Otherwise repeat the iteration.

\section{Model verification and application}

\subsection{Example}

The coupled model can be used to predict the productivity of horizontal wells in fault block reservoirs. Here, three

\begin{tabular}{|c|c|c|c|}
\hline Well name & A & $\mathrm{B}$ & $\mathrm{C}$ \\
\hline Arrangement with the fault & Parallel & Perpendicular & $\begin{array}{c}\text { Drill } \\
\text { out }\end{array}$ \\
\hline Net thickness, $\mathrm{m}$ & 11.5 & 13.7 & 8.3 \\
\hline Permeability, $10^{-3} \mu \mathrm{m}^{2}$ & 92.6 & 103.5 & 87.2 \\
\hline Oil viscosity, $\mathrm{mPa} \cdot \mathrm{s}$ & 8.2 & 8.2 & 8.2 \\
\hline Horizontal length, $\mathrm{m}$ & 256 & 225 & 198 \\
\hline Wellbore radius, $\mathrm{m}$ & 0.1 & 0.1 & 0.1 \\
\hline $\begin{array}{l}\text { Distance from the fault in } \\
\text { the left side, } m\end{array}$ & 85 & 61 & 53 \\
\hline $\begin{array}{l}\text { Distance from the fault in } \\
\text { the right side, } m\end{array}$ & 45 & 253 & 128 \\
\hline Reservoir pressure, $\mathrm{MPa}$ & 24.5 & 24.5 & 24.5 \\
\hline Bottom-hole flowing pressure, $\mathrm{MPa}$ & 21.6 & 22.1 & 21.4 \\
\hline
\end{tabular}
examples were considered, in each example there is only one horizontal well, well $\mathrm{A}, \mathrm{B}$, or $\mathrm{C}$ penetrating through the oil reservoir in different directions. Specifically, well A runs parallel to the fault, well $\mathrm{B}$ is perpendicular to the fault, and well $\mathrm{C}$ drills through the fault.

Fluid and rock properties and wellbore geometry are listed

\begin{tabular}{|c|c|c|c|c|c|}
\hline \multirow{2}{*}{$\begin{array}{l}\text { Well } \\
\text { name }\end{array}$} & \multirow{2}{*}{$\begin{array}{c}\text { Actual } \\
\text { productivity } \\
\mathrm{m}^{3} / \mathrm{d}\end{array}$} & \multicolumn{2}{|c|}{ The coupled model } & \multicolumn{2}{|c|}{$\begin{array}{c}\text { The Eclipse reservoir } \\
\text { simulator }\end{array}$} \\
\hline & & $\begin{array}{c}\text { Productivity } \\
\mathrm{m}^{3} / \mathrm{d}\end{array}$ & $\begin{array}{l}\text { Relative } \\
\text { error, \% }\end{array}$ & $\begin{array}{c}\text { Productivity } \\
\mathrm{m}^{3} / \mathrm{d}\end{array}$ & $\begin{array}{r}\text { Relative } \\
\text { error, \% }\end{array}$ \\
\hline A & 67.1 & 75.2 & 12.1 & 84.5 & 26.0 \\
\hline B & 90.7 & 83.3 & -8.2 & 99.9 & 10.1 \\
\hline $\mathrm{C}$ & 63.5 & 68.1 & 7.3 & 75.2 & 18.5 \\
\hline
\end{tabular}
in Table 1.

Table 1 Parameters for productivity calculation of horizontal wells

With the parameters in Table 1 , the productivity evaluation of the three wells A, B and C was conducted respectively with the coupled model and the Eclipse reservoir simulator. The results are shown in Table 2 and plotted in Figs. 3-5.

Table 2 Comparison of simulation results for three wells

Table 2 indicates that the coupled model has a high accuracy $(-15 \%<$ relative error $<15 \%)$ and the results calculated by the coupled model are consistent with those calculated by the Eclipse reservoir simulator.

The wellbore flow rate increases monotonically from the toe to the heel of the horizontal well (Figs. 3-5). Due to 
the pseudo-hemispherical flow at each end of the horizontal well (well toe and well heel) and pseudo-linear flow in the center, the drainage area at each end is larger than that at the center. The radial inflow at each end of the horizontal well is considerably higher than that in the center, a U-shaped radial flow distribution is formed along the horizontal well (Figs. $3-5)$.

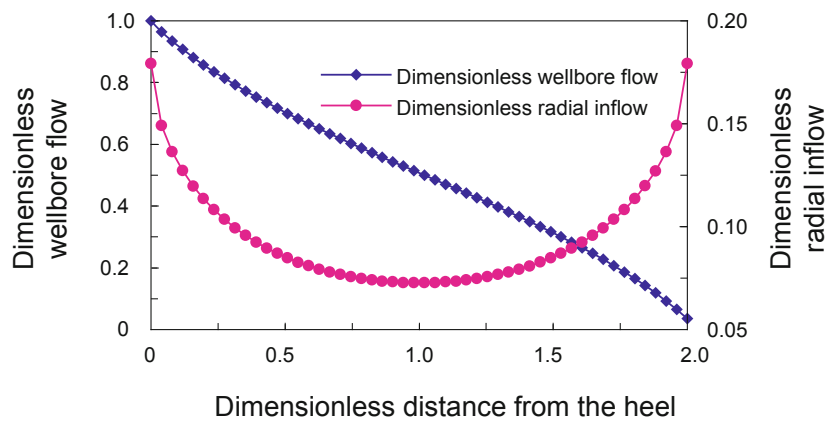

Fig. 3 Distribution of dimensionless wellbore flow and dimensionless radial inflow profiles of well A

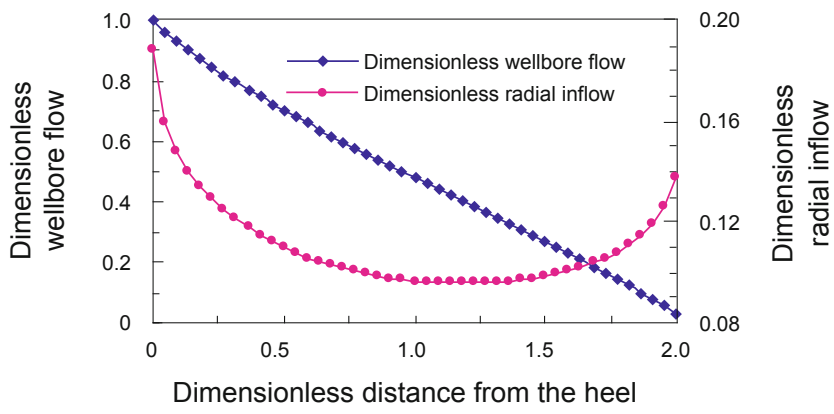

Fig. 4 Distribution of dimensionless wellbore flow and dimensionless radial inflow profiles of well $\mathrm{B}$

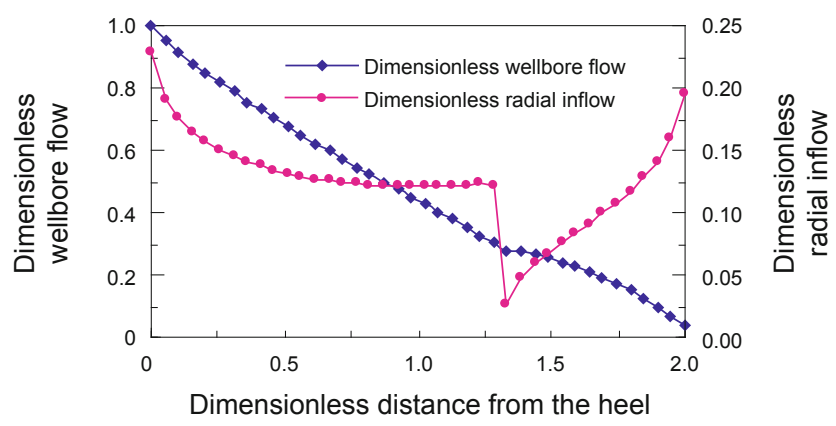

Fig. 5 Distribution of dimensionless wellbore flow and dimensionless radial inflow profiles of well $\mathrm{C}$

Horizontal well A runs parallel to the fault and, therefore, the distance between the horizontal well and the fault has no influence on the distribution of radial inflow along the hole.

Horizontal well B is perpendicular to the fault and, therefore, the well toe is much closer to the fault at the right side than the well heel to the fault at the left side. So the effect of the right side fault upon the well toe is much greater than that of the left side fault upon the well heel. As Fig. 4 shows, the radial inflow at the well toe is considerably lower than that at the well heel.

Horizontal well $\mathrm{C}$ is drilled through the right side fault. In Fig. 5, a sharp change is observed in the radial flow distribution curve, which occurs at the point where the horizontal well drilled through the fault.

\subsection{Application study}

In the application of horizontal wells in fault block reservoirs, the key is the optimization of well location. The horizontal interval should be parallel to the fault so as to enhance the oil recovery. However, it is a complicated problem to determine the optimal distance between the horizontal well and the fault. The drainage area of a horizontal well decreases due to fault sealing. For improving the productivity of an individual horizontal well, it is much better to drill the horizontal well away from the fault as far as possible. However, to enhance the recovery of oil from the oil formation near the fault, the horizontal well should be drilled as close as possible to the fault. Based on the reservoir fluid and rock properties (Table 1, Well A), the influence on the productivity of the distance between the horizontal well and the left (or right) fault was investigated when the distance between the horizontal well and the right (or left) fault was unchanged. Three cases were studied, in which the horizontal interval is 200,300 , and $400 \mathrm{~m}$, respectively.

Fig. 6 shows that the productivity of the horizontal well increases logarithmically as the distance between the horizontal well and the fault $(D)$ increases. Specifically, the well productivity increases rapidly when the distance between the horizontal well and the fault is less than or equal to 0.3 times the horizontal well length $(L)$. And the well productivity increases slowly when the distance is greater than $0.3 L$. Therefore, the optimal distance between the horizontal well and the fault is recommended at $0.25-0.3 L$, which can enhance the degree of recovery of oil around the fault and keep the productivity of the horizontal well at a high level at the same time.

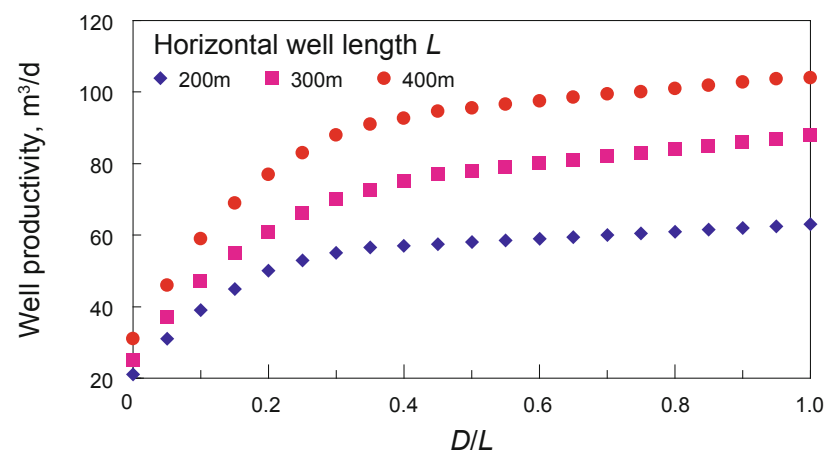

Fig. $6 \mathrm{D} / L$ versus well productivity

\section{Conclusions}

1) A semi-analytical model coupling reservoir and wellbore flow dynamics was developed. The model took into account the influence of fault sealing and wellbore pressure drop. The distribution of wellbore flow and radial inflow along the horizontal well also were obtained. 
2) Application of the novel semi-analytical model has demonstrated its reliability and usefulness. The relative error calculated by the model is within $\pm 15 \%$. The model can be used as an effective method for evaluating the productivity of horizontal wells in fault block reservoirs.

3) The productivity of the horizontal well increases logarithmically with the distance between the horizontal well and the fault. The optimal horizontal well position is $0.25-0.3$ times the horizontal well length away from the fault.

\section{Acknowledgements}

The authors are grateful for financial support from the National Science \& Technology Major Project of China (No. 2009ZX05009-006) and the China National Offshore Oil Corporation (CNOOC).

\section{References}

Dikken B J. Pressure drop in the horizontal wells and its effect on their production performance. Paper SPE 19824 presented at SPE Annual Technical Conference and Exhibition held in San Antonio, October 8-11, 1989

Fan Z F and Lin Z F. Productivity formula of horizontal wells in reservoirs with edge water drive. Petroleum Geology \& Oilfield Development in Daqing. 1994. 13(2): 33-37 (in Chinese)

Fokker P A, Verga F and Egberts P J P. New semianalytic technique to determine horizontal well productivity index in fractured reservoirs. Paper SPE 84597 presented at SPE Annual Technical Conference and Exhibition held in Denver, Colorado, October 5-8, 2003

Huang S J, Cheng L S, Zhao F L, et al. The flow model coupling reservoir percolation and variable mass pipe flow in production section of the stepped horizontal well. Journal of Hydrodynamics. 2005. 20(4): 463-471 (in Chinese)

Kuznetsov D S, Cheremisin A N and Chesnokov A A. Advanced horizontal well model. Paper SPE 127742 presented at SPE North Africa Technical Conference and Exhibition held in Cairo, Egypt,
February 14-17, 2010

Liu X P, Zhang Z S, Liu X E, et al. A model to calculate pressure drops of horizontal well bore variable mass flow coupled with flow in a reservoir. Journal of Southwest Petroleum Institute. 2000. 22(2): 3639 (in Chinese)

Michelevichius D and Zolotukhin A B. Evaluating productivity of a horizontal well. Paper SPE 79000 presented at SPE International Thermal Operations and Heavy Oil Symposium and International Horizontal Well Technology Conference held in Calgary, Alberta, Canada, November 4-7, 2002

Ouyang L B, Arbabl S and Aziz K. A single-phase wellbore-flow model for horizontal, vertical, and slanted wells. Paper SPE 36608 presented at SPE Annual Technical Conference and Exhibition held in Denver, Colorado, October 6-9, 1996

Ozkan E, Sarica C, Haciislamoglu M, et al. Effect of conductivity on horizontal well pressure behavior. SPE Advanced Technology Series. 1995. 3(1): 85-94 (Paper SPE 24683)

Tabatabaei M and Ghalambor A. A new method to predict performance of horizontal and multilateral wells. Paper IPTC 13122 presented at the International Petroleum Technology Conference held in Doha, Qatar, December 7-9, 2009

Xie X Q, Ding A M, Jiang H Q, et al. The effectiveness of developing complex small fault block reservoirs with a horizontal well pattern. Journal of Southwest Petroleum University. 2008. 30(3): 102-105 (in Chinese)

Ye S J, Jiang H Q and Chen M F. Prediction of the productivity of horizontal wells based on gray-relation analysis and neural network. Journal of Daqing Petroleum Institute. 2009. 33(3): 53-55 (in Chinese)

Yildiz T and Ozkan E. A simple correlation to predict wellbore pressure drop effects on horizontal well productivity. Paper SPE 48938 presented at SPE Annual Technical Conference and Exhibition held in New Orleans, Louisiana, September 27-30, 1998

Zhou H M, Chang X J, Hao J M, et al. Horizontal well development technique and its practice for complex fault-block reservoirs in Jidong Oilfield. Petroleum Exploration and Development. 2006. 33(5): 622-629 (in Chinese)

(Edited by Sun Yanhua) 